\title{
Strategies in Patients with Right Ventricular Failure on Mechanical Ventilation
}

\author{
Nitin Tanajirao Patil \\ Department of Anaesthesia, Manipal Academy of Higher Education, Manipal, Karnataka, India
}

\section{Abstract}

Right ventricular failure is a complex clinical syndrome, and is a challenge for the intensivist to diagnose in critically ill patients, more so in patients receiving mechanical ventilation. Acute RV failure is a sudden deterioration of RV function and an inability of the RV to pump adequate cardiac output to the pulmonary circulation, thereby leading to inadequate cardiac output to the systemic circulation. The most common causes of acute RV failure are acute RV myocardial infarction, massive pulmonary embolism, congenital heart diseases, and severe pulmonary arterial hypertension. Over the years, RV has been considered a passive chamber of the heart and has received less focus about the way it functions and how efficiently the RV dysfunction can be managed. The National Heart Lung and Blood Institute in 2006 convened a working group to better understand the mechanisms of right ventricular dysfunction and the various ways and means to diagnose and manage right ventricular dysfunction.

Keywords: Extracorporeal membrane oxygenation, pulmonary arterial hypertension, pulmonary embolism, right ventricular failure

\section{INTRODUCTION}

Historically and until recently, much less attention has been devoted toward the right ventricle (RV). It has received a step-brotherly approach in comparison to the left ventricle (LV). The right ventricle has been considered a passive chamber of the heart and not enough focus was given on how the right ventricle functions and what are the best ways to detect and manage right ventricular dysfunction. The National Heart Lung and Blood Institute in 2006 convened a working group to better understand the mechanisms of right ventricular dysfunction and the various ways and means to diagnose and manage right ventricular dysfunction. ${ }^{[1]}$

The normal RV is a thin-walled, crescent-shaped, and compliant chamber as it pumps blood into the pulmonary circuit with low resistance and high compliance as compared to the LV which has to pump into the systemic circuit. ${ }^{[2]}$ The major portion of RV stroke volume is due to the longitudinal shortening and not circumferential shortening as in the $\mathrm{LV}^{[3]}$

The RV and LV are interrelated by the common interventricular septum (IVS) and they share the pericardial space. This association of RV and LV allows the RV ejection to be augmented by LV ejection. ${ }^{[4]}$ Thus, both ventricles are

\begin{tabular}{|l|l|}
\hline \multicolumn{2}{|c|}{ Access this article online } \\
\hline Quick Response Code: & Website: \\
\hline & www.ijrconline.org \\
\cline { 2 - 2 } & \\
\hline
\end{tabular}

interdependent and function together in a complex manner in healthy and disease states.

\section{Acute Right Ventricular Failure in Ventilated Patients (Acute Right Heart Syndrome)}

Acute RV failure is the sudden deterioration in RV function and an inability of the RV to pump adequate cardiac output to pulmonary circulation, leading to systemic hypoperfusion. The low cardiac output that ensues leads to further RV dysfunction, which in itself leads to significant in-hospital morbidity and mortality, especially in critical illness scenario. ${ }^{[5]}$

\section{Etiology}

Right ventricular failure in ventilated and critically ill patients can be due to right ventricular volume overload, right ventricular pressure overload, or right ventricular contractile dysfunction.

Address for correspondence: Dr. Nitin Tanajirao Patil, Department of Anaesthesia, Kasturba Medical College, Manipal University, Manipal - 576 104, Karnataka, India. E-mail: nitintpati@@yahoo.com

This is an open access article distributed under the terms of the Creative Commons Attribution-NonCommercial-ShareAlike 3.0 License, which allows others to remix, tweak, and build upon the work non-commercially, as long as the author is credited and the new creations are licensed under the identical terms.

For reprints contact: reprints@medknow.com

How to cite this article: Patil NT. Strategies in patients with right ventricular failure on mechanical ventilation. Indian J Respir Care 2018;7:22-7. 
Patil NT: Strategies in patients with right ventricular failure

\section{Causes of acute right ventricular failure in intensive care units}

Right ventricular volume overload may be due to pulmonary or tricuspid regurgitation, left-to-right shunt, or anomalous pulmonary venous return. ${ }^{[6]}$

Right ventricular pressure overload may be due to endothelial dysfunction, vasoconstriction, mechanical obstruction, acute respiratory distress syndrome (ARDS), massive pulmonary embolism (PE), chronic pulmonary arterial hypertension $(\mathrm{PAH})$, postcardiac surgery, and mechanical ventilation. ${ }^{[6]}$

Right ventricular contractile dysfunction may be due to right ventricular myocardial infarction (RVMI), right ventricular cardiomyopathy, sepsis (cytokine-induced myocardial depression), postcardiopulmonary bypass, myocarditis, pericardial disease such as constrictive pericarditis, tamponade, and left ventricular assist device (acute unloading of LV). ${ }^{[6]}$

Left ventricular dysfunction caused due to myocardial ischemia and LV dilatation lead to restricted RV diastolic function. ${ }^{[6]}$

\section{Clinical features of right ventricular failure}

Clinical features of right ventricular failure (RVF) in the general population are mainly due to fluid retention or venous congestion seen as raised jugular venous pulse, epigastric discomfort, enlarged tender liver, ascites, and peripheral edema. The low cardiac output manifests as dyspnea on exertion, easy fatigability, and dizziness. The patient may also have atrial or ventricular tachycardia (gallop rhythm).

Some of these clinical features are difficult to imply toward RVF unless there is a high level of suspicion, especially in a sedated and ventilated patient in the Intensive Care Unit (ICU).

\section{Clinical features of right ventricular failure in mechanically ventilated patients}

The cardinal signs of right ventricular failure (RVF) are increasing oxygen requirement and sudden cardiovascular collapse. ${ }^{[7]}$ The other signs include atrial or ventricular arrhythmias, raised jugular venous pulse, gallop rhythm at left sternal edge, pansystolic murmur of tricuspid regurgitation, hepatomegaly, and persistent/ recurrent failure in weaning from ventilator. ${ }^{[8]}$

A high index of suspicion of RVF must be maintained in patients with a past history of pulmonary artery hypertension or recent deep vein thrombosis. ${ }^{[9]}$

\section{Diagnostic tools}

1. A chest X-ray will show enlarged pulmonary artery and regional oligemia in massive PE. It also helps to rule out atelectasis, pleural effusion, pulmonary edema, and pneumothorax

2. Electrocardiography may show features suggestive of right ventricular hypertrophy such as right-axis deviation, dominant $\mathrm{R}$ in V1, dominant $\mathrm{S}$ in V5, and $\mathrm{P}$ pulmonale. They may also show features suggestive of right ventricular myocardial infarct such as elevated ST in $\mathrm{V}_{3} \mathrm{R}$ and $\mathrm{V}_{4} \mathrm{R}, \mathrm{RV}$ strain as evidenced by $\mathrm{T}$ inversion in V1 to V4, and S1Q3T3. RV dysfunction may manifest with a Qr in V1 (highly associated with troponin leakage and myocardial shear stress $)^{[10]}$

3. Arterial blood gas analysis - Acidemia with lactic acidosis due to hypoperfusion and low cardiac output

4. Dynamic hemodynamic parameters - Pulse pressure variation (PPV), stroke volume variation (SVV), and cardiac output can be derived from arterial pulse contour analysis in mechanically ventilated patients. A lack of response to fluid challenge in high PPV and SVV indicates toward RV dysfunction ${ }^{[11]}$

5. Echocardiography - Transthoracic echo (TTE) and transesophageal echo (TEE) are bedside diagnostic tools for rapid diagnosis of right ventricular dysfunction/failure and help in therapeutic strategies. TTE is easy and noninvasive but gives inadequate imaging window in patients on mechanical ventilation with positive end-expiratory pressure (PEEP). TEE is semi-invasive and provides a better assessment of RV size, shape, and function.

Echocardiographic parameters indicative of RVF are as follows: ${ }^{[12,13]}$

a. Tricuspid annular plane systolic excursion (TAPSE) - It is a simple and reproducible parameter assessed by measuring longitudinal displacement of RV base toward $\mathrm{RV}$ apex in systole. TAPSE $<16 \mathrm{~mm}$ indicates RV dysfunction

b. Dilated RV $>32 \mathrm{~mm}$ at base, $>35 \mathrm{~mm}$ at mid-level, and $>86 \mathrm{~mm}$ longitudinally

c. Right ventricular outflow tract diameter $>27 \mathrm{~mm}$ at end diastole

d. RV/LV basal diameter - ratio $>1$

e. Loss of normal spherical shape of LV - "D" sign indicates high pulmonary artery (PA) pressures

f. Inferior vena cava diameter $>20 \mathrm{~mm}$ and loss of collapsibility indicate high right atrial pressure.

In mechanically ventilated patients, the measurement of right atrial and the PA pressure can be inaccurate due to PPV. Thus, pulmonary artery catheterization provides reliable measurement of pulmonary hemodynamics and information of RV and LV filling pressure with cardiac output. ${ }^{[14]}$

\section{Other imaging modalities}

Computed tomography pulmonary angiogram - This is a diagnostic tool in suspected PE. It has $50 \%-100 \%$ of sensitivity and $81 \%-100 \%$ of specificity. ${ }^{[15]}$ Signs of suspected RV dysfunction due to PE include flattening of IVS toward $\mathrm{LV}$, reflux of contrast in inferior vena cava, and the RV/LV diameter $>1$.

Cardiovascular magnetic resonance (CMR) imaging - CMR is the gold standard and most sensitive for the assessment of RV size and function as it is not influenced by acoustic window or preexisting cardiopulmonary disease. ${ }^{[16]}$ However, CMR has limitations in a critically ill patient on mechanical ventilation, 
due to risk during transportation and prolonged duration for magnetic resonance imaging.

Right heart catheterization can be done for the diagnosis of PAH. This method can be a constraint in critically ill patients on mechanical ventilation because of risks during transportation.

\section{Biochemical markers}

Raised B-type natriuretic peptide, troponin, and D dimer though nonspecific indicate myocardial stress and injury in RV failure scenarios. Plasma lactate levels $>2 \mathrm{mmol} / \mathrm{L}$ indicate tissue hypoperfusion and these patients are at a high risk of morbidity and mortality. Liver enzymes, bilirubin, and serum creatinine may be raised in RV failure as a result of inadequate perfusion or venous congestion in RV overload.

\section{Management Strategies}

The broad physiological principles of management of RV failure in a critically ill patient on ventilator are optimization of RV preload, optimization of RV afterload, and contractility.

\section{Optimization of RV preload}

Optimization of intravascular fluid is very important for successful management of RV failure. In critically ill patients, the intravascular fluid status may be inadequate due to increased permeability and insensible fluid loss.

Sedatives can cause decreased venous tone and reduced venous return. Mechanical ventilation increases intrathoracic pressure and reduces RV preload. Based on Frank Starling law, increase in RV preload may improve RV ejection fraction, but this may not be true in all situations.

If RV failure occurs with a normal RV afterload (normal pulmonary vascular resistance [PVR]) as in RVMI, rapid volume resuscitation is necessary to maintain adequate cardiac output, but if RV failure occurs with an increased RV afterload as in acute PE, volume overload can cause IVS displacement toward LV and decreased LV filling, simultaneously RV distension increases free wall tension, increased oxygen demand, reduced RV perfusion, and further RV ischemia. ${ }^{[14]}$

A central venous line can provide central venous pressure and superior vena cava saturation $\left(\mathrm{S}_{\mathrm{V}} \mathrm{O}_{2}\right)$ to assess right-sided filling pressures. Normal $\mathrm{S}_{\mathrm{V}} \mathrm{O}_{2}$ is $70 \%-80 \%$, and lower values suggest low cardiac output.

Marik and Cavallazzi in a recent meta-analysis showed that there is not enough data to support CVP as a guide for fluid assessment and therapy. ${ }^{[17]}$ Pulmonary artery catheterization and TTE/TEE are more reliable tools to guide fluid therapy. ${ }^{[18]}$ In RV volume overload leading to acute kidney injury (cardiorenal syndrome), continuous venovenous hemofiltration is advisable to achieve better clinical improvement than aggressive diuretic therapy in heart failure patients. ${ }^{[19]}$

\section{Optimization of RV afterload}

Excessive RV afterload is an important factor in most cases of acute RV failure, in critically ill patients. Efforts need to focus on reducing the afterload with pulmonary vasodilators and prompt correction of the factors that increase PVR such as hypoxemia, hypercapnia, and acidosis. $\mathrm{SpO}_{2}$ needs to be kept above $92 \%$ with $\mathrm{PCO}_{2}, \mathrm{pH}$ near-normal values, and ventilator setting to achieve a lung volume near functional residual capacity (FRC).

\section{Pulmonary vasodilators}

The role of pulmonary vasodilators in acute RV failure is to decrease PVR, improve RV stroke volume and RV output, and avoid systemic hypotension and maintain coronary perfusion.

Several classes of pulmonary vasodilators are developed over the last two decades for PAH.

\section{Inhaled nitric oxide}

A potent pulmonary vasodilator acts by increasing intracellular cyclic guanosine monophosphate (cGMP) and has a rapid onset and short half-life. It improves $\mathrm{PaO}_{2} / \mathrm{FiO}_{2}$ ratio and cardiac output in ventilated patients with acute RV failure due to ARDS. ${ }^{[20]}$ It can be an ideal agent to rapidly reduce RV afterload for a short-term therapy.

Rossaint et al. have shown that it improves RV ejection fraction and RV end-diastolic volume in patients with RV failure due to severe ARDS. ${ }^{[21]}$ Bhorade et al. have shown that it improves pulmonary hemodynamics and mixed venous $\mathrm{SpO}_{2}$ in acute RV failure. ${ }^{[22]}$

\section{Prostacyclin derivatives}

They are potent pulmonary vasodilators with rapid onset and short half-life and hence, the initial therapy of choice in severe PAH with RV failure. They act by increasing intracellular cyclic adenosine monophosphate (cAMP) levels and may also have inotropic action. At present, three prostacyclin derivatives are available: epoprostenol, treprostinil, and iloprost.

Radermacher et al. showed that intravenous (IV) epoprostenol reduces PVR and improves RV function in patients with ARDS on mechanical ventilation. ${ }^{[23]}$ Muzaffar et al. have used inhaled epoprostenol to successfully manage patients with RV failure in postcardiac surgery patients. ${ }^{[24]}$ Epoprostenol and iloprost are potent pulmonary and systemic vasodilators with antithrombotic and antiproliferative actions. They reduce PVR and improve RV function in acute RV failure. All the three drugs can be used by inhalational therapy to avoid systemic hypotension.

\section{Phosphodiesterase 5 inhibitors}

These agents inhibit the metabolism of cGMP and potentiate the beneficial effect of nitric oxide. Oral preparations must be used carefully as they cause systemic vasodilation and have longer half-life.

Oral sildenafil and tadalafil reduce PVR, improve myocardial perfusion, and may improve RV contractility. ${ }^{[25]}$ Intravenous preparation of sildenafil with shorter half-life is available and can be useful in RV failure in ICU patients on mechanical ventilation. $^{[26]}$ 
Patil NT: Strategies in patients with right ventricular failure

Other pulmonary vasodilators such as endothelin receptor antagonist (ambrisentan and bosentan) and soluble guanylate cyclase stimulator (Riociguat) are not tried and tested in acute RV failure.

\section{Optimization of RV contractility}

The RV contractility is reduced in acute RV failure due to overstretching of RV free wall, derangement in cellular metabolism, and inadequate coronary perfusion, leading to insufficient oxygen delivery. Increase in RV preload or afterload increases the RV free wall tension and oxygen demand and simultaneously reduces LV filling, LV output, and coronary perfusion. Metabolic derangement due to acid-base imbalance, oxygen-free radicals, and cytokines can cause RV failure in critically ill patients. ${ }^{[27]}$ In patients of acute RV failure with chronic pulmonary vascular disease, the RV systolic pressure may be near systemic pressure. Hence, the primary goal should be to keep systemic blood pressure above RV systolic pressure and thus, the role of vasopressors is very important here.

\section{Vasopressors}

An ideal agent would be the one which increases the systemic vascular resistance and systemic blood pressure without raising PVR and improves RV contractility. Norepinephrine principally acts on $\alpha_{1}$ receptors and causes vasoconstriction with limited $\beta_{1}$ stimulation and cardiac inotropy. Phenylephrine is purely an $\alpha_{1}$ agonist, causes vasoconstriction and improves coronary perfusion but it may also increase the PVR. Vasopressin at lower doses (0.01-0.03 U/min) causes pulmonary vasodilatation and at higher doses causes pulmonary and systemic vasoconstriction. Epinephrine is a mixed $\alpha$ - and $\beta$-receptor agonist that causes vasoconstriction and inotropy. All in all, norepinephrine is the initial agent in hypotensive patients with RV failure.

\section{Inotropes}

These are indicated in patients with acute RV failure and have a low cardiac output.

Dobutamine acts through $\beta_{1}$ and $\beta_{2}$ receptors, causes vasodilatation, and improves cardiac output at lower doses. At higher doses, it can cause tachycardia and hypotension.

Milrinone is a selective phosphodiesterase 3 inhibitor. It slows intracellular cAMP metabolism, causes pulmonary vasodilatation, and improves RV contractility. It is the drug of choice in pulmonary vascular disease with severe PAH and biventricular failure. It is preferred over dobutamine as it has less chronotropic effect.

Inotropes can cause tachycardia and should be considered only when there is evidence of inadequate oxygen delivery in spite of correction of RV preload, RV afterload, and ischemia.

Levosimendan is a calcium sensitizer. It improves myocardial contractility without increasing cytosolic calcium and oxygen demand. In patients having RV failure with chronic thromboembolic pulmonary hypertension (CTPH), levosimendan has been shown to improve RV function. ${ }^{[28]}$

Maintenance of sinus rhythm and heart rate control is important for RV failure scenario.

\section{Goals OF MECHANICAL VENTILATION}

The goals of mechanical ventilation are as follows: avoid hypoxia, hypercapnia, and high PEEP (10 $\left.\mathrm{cmH}_{2} \mathrm{O}\right)$. Adopt lung protective ventilator strategy (low tidal volume, low plateau pressure, and PEEP). RV afterload is determined by PVR, which is affected by the changes in lung volume. The PVR is high, both at low as well as high lung volumes. At low volumes, PVR is high due to elastic recoil of lung parenchyma leading to extra-alveolar vessel collapse and terminal airway collapse leading to alveolar hypoxia and hypoxic pulmonary vasoconstriction. At high volumes, PVR is high because stretching of alveolar walls leads to collapse of alveolar vessels. ${ }^{[29]}$ The total PVR is lowest at FRC, whereas vascular resistance in intra- and extra-alveolar vessels is intermediate.

Schmitt et al. demonstrated that high $\operatorname{PEEP}\left(13 \mathrm{~cm} \pm 4 \mathrm{cmH}_{2} \mathrm{O}\right)$ is associated with increased RV afterload and worsening of RV systolic function. ${ }^{[30]}$ The use of lung protective strategies (low $\mathrm{V}_{\mathrm{T}} 6-8 \mathrm{ml} / \mathrm{kg}$, low plateau pressure, and low PEEP) in ARDS net trial showed a significant decrease of incidence of acute RV failure in ARDS group. ${ }^{[31]}$

During lung protective strategy in acute RV failure condition, it is very important to avoid hypercapnia as it can increase PVR and worsen RV function. Hence, in these patients, it is recommended to gradually adopt lung protective ventilation strategies keeping an eye on hypercapnia and RV function. ${ }^{[32]}$

It is important to remember that these patients of acute RV failure on mechanical ventilation may be difficult to wean off the ventilator, as weaning may worsen (increase) RV afterload due to increase in work of breathing, hypoxemia, or high intrinsic PEEP, which can lead to further RV enlargement and shift of IVS toward LV, affecting LV filling and LV output. This can cause pulmonary edema and thus leads to failure in weaning from mechanical ventilation. ${ }^{[33]}$

\section{Mechanical support}

In mechanically ventilated patients with severe RV failure where the medical therapy is ineffective and patients have hypoxemia and/or hypercapnia and need high PEEP, they are the ones who may do well with mechanical circulatory support such as extra corporeal membrane oxygenation (ECMO) until the recovery of respiratory function. ${ }^{[34]}$

In patients with RV failure due to ARDS, with severe intractable hypercapnic acidosis, where the ventilator therapy is ineffective, Extracorporeal Carbon dioxide removal devices like -Interventional Lung Assist (NovaLung $\mathrm{GmbH}$, Hechingen, Germany), may be useful as they are pumpless and are less invasive than ECMO and ultraprotective lung protection strategy can be instituted. (VT $-4 \mathrm{ml} / \mathrm{kg}$ of predicted body weight). ${ }^{[35]}$ 
Patil NT: Strategies in patients with right ventricular failure

In patients with RV failure due to massive PE, chronic thromboembolic pulmonary hypertension (CTPH), and $\mathrm{PAH}$, venovenous or venoarterial (VA) ECMO is used successfully as a bridge to pulmonary endarterectomy or lung transplantation. ${ }^{[36,37]}$

Mydin et al. have shown that VA ECMO improves RV function and oxygen delivery in awake spontaneously breathing patients as a bridge to pulmonary endarterectomy. ${ }^{[38]}$

In patients with acute RV failure, due to primary $R V$ pathology and RV dysfunction refractory to medical treatment, mechanical support of RV such as right ventricular assist device is used as a bridge to recovery or bridge to heart transplant. ${ }^{[39]}$

Recently, pumpless lung assist devices have been developed that connect the PA to left atrium with low resistance membrane oxygenator and it has been tried in patients with PAH as a bridge to lung transplant. The low resistance circuit offloads the RV and improves LV filling. ${ }^{[40]}$

Salient points in the management of acute RV failure are as follows:

- Correction of precipitating causes of RV failure

- Normalizing the contributory factors such as hypoxemia, hypercapnia, anemia, acidosis, sepsis, and arrhythmias

- Optimization of fluid status

- Maintaining adequate perfusion pressure

- Inotropes and vasopressors

- Pulmonary vasodilators - chemical, and inhalational

- Lung protective mechanical ventilation

- Mechanical circulatory assist devices.

\section{Conclusion}

$\mathrm{RV}$ failure is seen increasingly in critically ill patients on mechanical ventilation in an ICU and carries significant morbidity and mortality. RV failure is a complex clinical syndrome, challenging to diagnose in critically ill patients, and it can be taxing for intensive care specialists. Common causes of acute RV failure are RVMI, massive PE, severe PAH, and congenital heart diseases.

It is important to diagnose RV failure early and identify and correct the reversible factors followed by optimization of $\mathrm{RV}$ preload, reducing the RV afterload and improving RV contractility.

When all the options of medical management are exhausted, extra corporeal life support in the form of ECMO is effective in restoring circulatory support to all vital organs and is indicated as a bridge to recovery in patients with reversible RV failure, and bridge to surgical interventions such as pulmonary endarterectomy, lung transplant, heart transplant, or heart-lung transplant.

Early referral to specialized centers should be sought in need of mechanical circulatory support. Well-designed randomized controlled trials are the need of time for better understanding of the various mechanisms of acute RV failure and guide the therapy in critically ill patients on mechanical ventilator.

\section{Financial support and sponsorship}

Nil.

\section{Conflicts of interest}

There are no conflicts of interest.

\section{References}

1. Voelkel NF, Quaife RA, Leinwand LA, Barst RJ, McGoon MD, Meldrum DR, et al. Right ventricular function and failure: Report of a National Heart, Lung and Blood Institute working group on cellular and molecular mechanism of right heart failure. Circulation 2006;114:1883-91.

2. Greyson CR. The right ventricle and pulmonary circulation: Basic concepts. Rev Esp Cardiol 2010;63:81-95.

3. Kukulski T, Hübbert L, Arnold M, Wranne B, Hatle L, Sutherland GR, et al. Normal regional ventricular function and its change with age: A Doppler myocardial imaging study. J Am Soc Echocardiogr 2000;13:194-204.

4. Santamore WP, Dell'Italia LJ. Ventricular interdependence: Significant left ventricular contributions to right ventricular systolic function. Prog Cardiovasc Dis 1998;40:289-308.

5. Greyson CR. Pathophysiology of right ventricular failure. Crit Care Med 2008;36:S57-65.

6. Zochios V, Jones N. Acute right heart syndrome in the critically ill patient. Heart Lung Vessel 2014;6:157-70.

7. Markel TA, Wairiuko GM, Lahm T, Crisostomo PR, Wang M, Herring CM, et al. The right heart and its distinct mechanisms of development, function, and failure. J Surg Res 2008;146:304-13.

8. Methvin AB, Owens AT, Emmi AG, Allen M, Wiegers SE, Dries DL, et al. Ventilatory inefficiency reflects right ventricular dysfunction in systolic heart failure. Chest 2011;139:617-25.

9. Kevin LG, Barnard M. Right ventricular failure. Contin Educ Anaesth Crit Care Pain 2007;7:89-94.

10. Kucher N, Walpoth N, Wustmann K, Noveanu M, Gertsch M. QR in V1 - An ECG sign associated with right ventricular strain and adverse clinical outcome in pulmonary embolism. Eur Heart J 2003;24:1113-9.

11. Michard F, Richards G, Biais M, Lopes M, Auler JO. Using pulse pressure variation or stroke volume variation to diagnose right ventricular failure? Crit Care 2010;14:451.

12. Rudski LG, Lai WW, Afilalo J, Hua L, Handschumacher MD, Chandrasekaran $\mathrm{K}$, et al. Guidelines for the echocardiographic assessment of the right heart in adults: A report from the American Society of Echocardiography endorsed by the European Association of Echocardiography, a registered branch of the European Society of Cardiology, and the Canadian Society of Echocardiography. J Am Soc Echocardiogr 2010;23:685-713.

13. Bleeker GB, Steendijk P, Holman ER, Yu CM, Breithardt OA, Kaandorp TA, et al. Acquired right ventricular dysfunction. Heart 2006;92 Suppl 1:i14-8.

14. Ventetuolo CE, Klinger JR. Management of acute right ventricular failure in the Intensive Care Unit. Ann Am Thorac Soc 2014;11:811-22.

15. Kang DK, Thilo C, Schoepf UJ, Barraza JM Jr., Nance JW Jr., Bastarrika G, et al. CT signs of right ventricular dysfunction: Prognostic role in acute pulmonary embolism. JACC Cardiovasc Imaging 2011;4:841-9.

16. Mitoff PR, Beauchesne L, Dick AJ, Chow BJ, Beanlands RS, Haddad $\mathrm{H}$, et al. Imaging the failing right ventricle. Curr Opin Cardiol 2012;27:148-53

17. Marik PE, Cavallazzi R. Does the central venous pressure predict fluid responsiveness? An updated meta-analysis and a plea for some common sense. Crit Care Med 2013;41:1774-81.

18. Zochios V, Wilkinson V. Assessment of intravascular fluid status and fluid responsiveness during mechanical ventilation in surgical and intensive care patients. JICS 2011;12:295-300.

19. Giglioli C, Landi D, Cecchi E, Chiostri M, Gensini GF, Valente S, et al. 
Patil NT: Strategies in patients with right ventricular failure

Effects of ULTRAfiltration vs. DIureticS on clinical, biohumoral and haemodynamic variables in patients with deCOmpensated heart failure: The ULTRADISCO study. Eur J Heart Fail 2011;13:337-46.

20. Price LC, Wort SJ, Finney SJ, Marino PS, Brett SJ. Pulmonary vascular and right ventricular dysfunction in adult critical care: Current and emerging options for management: A systematic literature review. Crit Care 2010;14:R169.

21. Rossaint R, Slama K, Steudel W, Gerlach H, Pappert D, Veit S, et al. Effects of inhaled nitric oxide on right ventricular function in severe acute respiratory distress syndrome. Intensive Care Med 1995;21:197-203.

22. Bhorade S, Christenson J, O'connor M, Lavoie A, Pohlman A, Hall JB, et al. Response to inhaled nitric oxide in patients with acute right heart syndrome. Am J Respir Crit Care Med 1999;159:571-9.

23. Radermacher P, Santak B, Wüst HJ, Tarnow J, Falke KJ. Prostacyclin and right ventricular function in patients with pulmonary hypertension associated with ARDS. Intensive Care Med 1990;16:227-32.

24. Muzaffar S, Shukla N, Angelini GD, Jeremy JY. Inhaled prostacyclin is safe, effective, and affordable in patients with pulmonary hypertension, right-heart dysfunction, and refractory hypoxemia after cardiothoracic surgery. J Thorac Cardiovasc Surg 2004;128:949-50.

25. Greyson CR. Right heart failure in the Intensive Care Unit. Curr Opin Crit Care 2012;18:424-31

26. Vachiery JL, Huez S, Gillies H, Layton G, Hayashi N, Gao X, et al. Safety, tolerability and pharmacokinetics of an intravenous bolus of sildenafil in patients with pulmonary arterial hypertension. Br J Clin Pharmacol 2011;71:289-92.

27. Hoffman MJ, Greenfield LJ, Sugerman HJ, Tatum JL. Unsuspected right ventricular dysfunction in shock and sepsis. Ann Surg 1983;198:307-19.

28. Pitsiou G, Paspala A, Bagalas V, Boutou AK, Stanopoulos I. Inhaled iloprost plus levosimendan to decompensate right heart failure due to chronic thromboembolic pulmonary hypertension. Anaesth Intensive Care 2013;41:554-6.

29. Shekerdemian L, Bohn D. Cardiovascular effects of mechanical ventilation. Arch Dis Child 1999;80:475-80.

30. Schmitt JM, Vieillard-Baron A, Augarde R, Prin S, Page B, Jardin F, et al. Positive end-expiratory pressure titration in acute respiratory distress syndrome patients: Impact on right ventricular outflow impedance evaluated by pulmonary artery Doppler flow velocity measurements. Crit Care Med 2001;29:1154-8.

31. Acute Respiratory Distress Syndrome Network, Brower RG, Matthay MA, Morris A, Schoenfeld D, Thompson BT, et al. Ventilation with lower tidal volumes as compared with traditional tidal volumes for acute lung injury and the acute respiratory distress syndrome. N Engl J Med 2000;342:1301-8.

32. Mekontso Dessap A, Charron C, Devaquet J, Aboab J, Jardin F, Brochard L, et al. Impact of acute hypercapnia and augmented positive end-expiratory pressure on right ventricle function in severe acute respiratory distress syndrome. Intensive Care Med 2009;35:1850-8.

33. Teboul JL, Monnet X, Richard C. Weaning failure of cardiac origin: Recent advances. Crit Care 2010;14:211.

34. Gattinoni L, Carlesso E, Langer T. Clinical review: Extracorporeal membrane oxygenation. Crit Care 2011;15:243.

35. Tiruvoipati R, Botha JA, Pilcher D, Bailey M. Carbon dioxide clearance in critical care. Anaesth Intensive Care 2013;41:157-62.

36. Maggio P, Hemmila M, Haft J, Bartlett R. Extracorporeal life support for massive pulmonary embolism. J Trauma 2007;62:570-6.

37. Gregoric ID, Chandra D, Myers TJ, Scheinin SA, Loyalka P, Kar B, et al. Extracorporeal membrane oxygenation as a bridge to emergency heart-lung transplantation in a patient with idiopathic pulmonary arterial hypertension. J Heart Lung Transplant 2008;27:466-8.

38. Mydin M, Berman M, Klein A, Tsui S, Dunning J, Valchanov K, et al. Extracorporeal membrane oxygenation as a bridge to pulmonary endarterectomy. Ann Thorac Surg 2011;92:e101-3.

39. Moazami N, Pasque MK, Moon MR, Herren RL, Bailey MS, Lawton JS, et al. Mechanical support for isolated right ventricular failure in patients after cardiotomy. J Heart Lung Transplant 2004;23:1371-5.

40. Strueber M, Hoeper MM, Fischer S, Cypel M, Warnecke G, Gottlieb J, et al. Bridge to thoracic organ transplantation in patients with pulmonary arterial hypertension using a pumpless lung assist device. Am J Transplant 2009;9:853-7. 